\title{
Factors Affecting Production of Flood Tolerant Rice Variety in Assam: A Farm Level Study
}

\author{
Anusha Jammalamadaka*1 and Nivedita Deka ${ }^{2}$
}

${ }^{1}$ Department of Agricultural Economics, Professor Jayashankar Telangana State Agricultural University, Research Scholar, 500030 and Hyderabad, Telangana, India

${ }^{2}$ Assam Agricultural University, Department of Agricultural Economics, Faculty of Agriculture, 785013 and Jorhat, Assam, India

*Corresponding author: janusha071@gmail.com (ORCID ID: 0000-0001-6653-3342)

Received: $10-04-2020$

Revised: 20-07-2020

Accepted: 29-08-2020

\begin{abstract}
A field study was conducted in Jorhat district of Assam. The objective of the study is to obtain a better understanding of the factors affecting rice production at the farm level. The data were collected from 80 farmers using multistage random sampling technique. A regression analysis Cobb -Douglas model was used to identify the factors affecting rice production at farm level (Adopters and Non Adopters). The empirical evidence finds that FYM cost (0.074) and fertilizer cost (0.107) were found to be positive and significant indicating that with $1 \%$ increase in both the inputs would increase the rice production and thereby increase the gross return by 7.4 and $10.7 \%$, respectively. Problems faced by the farmers as collected by primary survey were ranked using the ranking method. Among adopters, the major problem observed was high seed cost according to $33.33 \%$ of total adopters and lack of extension contacts was a serious problem as reported by $26.00 \%$ of non adopters due to which they were lagging knowledge about flood tolerant rice varieties.

Highlights

(0 The FYM cost (0.074) and fertilizer cost (0.107) were found to be positive and significant. And would increase the rice production and thereby increase the gross return by 7.4 and $10.7 \%$, respectively.

0 The major problem among adopters observed was high seed cost according to $33.33 \%$.
\end{abstract}

Keywords: Adoption factors, Cobb Douglas production function, Flood, Flood tolerant rice varieties, Regression analysis.

Assam is a state of North-East India, located south of the eastern Himalayas, comprises of the Brahmaputra Valley and the Barak Valley and is one among the seventh state of northeast India. The rice growing seasons in Assam are mainly dividedon the basis of the type of rice viz., Ahu (Autumn rice) (Feb /March - June /July), Sali (Winter rice) (June /July - Nov /December) and Boro (Summer rice) (Nov /December -May /June). Assam economy is mainly based on agriculture as large number of people are agrarian. In Assam, flood is the most severe form of abiotic stress causing huge loss to the agricultural and allied sector. Rice production in these areas is very poor and fragile due to un-favourable environment including the abiotic stresses like flood, drought, submergence and salt affected soils. NFSM included flood tolerant variety Swarna-Sub1 in their mini-kit distribution programme in 2010. Rice productivity is highly correlated with production factors including seeds, fertilizers, pesticides, and labour (Effendy, 2010; Li et al. 2008). The coefficient of multiple determinations $(R 2)$ for both adopters and non-adopters were found

How to cite this article: Jammalamadaka, A. and Deka, N. (2020). Factors Affecting Production of Flood Tolerant Rice Variety in Assam: A Farm Level Study. Economic Affairs, 65(3): 445-449.

Source of Support: None; Conflict of Interest: None 
to be 0.63 and 0.68 indicating $63 \%$ and $68 \%$ that the variable considered in the model could explain considerable variations in the gross return from the rice production. FYM cost (0.074) and fertilizer cost (0.107) were found to be positive and significant indicating that with 1 per cent increase in both the inputs would increase the rice production and thereby increase the gross return by 7.4 and $10.7 \%$, respectively. An attempt was made to identify why the farmers were not adopting flood tolerant rice varieties in the study area. Personal interview was done with the respondents to get their opinion about the problems in adoption and non adoption of the flood tolerant rice varieties. Constraints faced by both adopters and non adopters were identified with ranking methodology. Therefore, the present study attempts to explore the status of actors affecting rice production at farm level of flood tolerant rice variety both adopters and non adopters in Jorhat district of Assam.

\section{MATERIALS AND METHODS}

Data were collected from the survey conducted at Jorhat district of Assam. Research sample of 80 farmers were drawn using multi-stage random sampling. At the first stage, out of the six development blocks Kaliapani block was purposively selected as KVK, Jorhat is situated here and farmers of few villages under the block were reported to grow flood tolerant rice variety. At the second stage, 4 villages viz., Bamunpukhuri, Bhogamukh, Khonamukh, and Charinga were selected at random (5\%) from each village were randomly selected to get a sample of 80 respondents. This process resulted in a sample of 80 numbers adopting both flood tolerant and normal rice. The farmers growing flood tolerant rice varieties are named as adopters and were (30) and the farmers not growing flood tolerant rice varieties are named as non adopters and were (50).

The selected farmers were classified into marginal (below 1 ha), small ( 1 to $<2$ ha) and medium (2-4 ha) based on their operational holding. No large farmers were found in the present sample (Table 1). The data collection used a structured questionnaire on farmer's production activities including input and output on paddy farm by both adopters and non adopters separately.

\section{Analytical Methods}

\section{Regression analysis}

The Cobb-Douglas equation was used to analyse the impact of production variables on the production of rice both by adopters and non adopters separately. A general form of the function written as:

$$
\begin{aligned}
& Y=f\left(X_{i}\right) \\
& Y=\beta_{\circ} X_{1}^{\beta 1} X_{2}{ }^{\beta 2} X_{3}{ }^{\beta 3} X_{4}{ }^{\beta 4} X_{4}{ }^{\beta 5} X_{5}^{\beta 5} e_{u}
\end{aligned}
$$

Where, $Y$ is the gross return and $X_{i}^{\prime}$ s are the amount in rupee terms of the various production inputs that are considered for the study.

Production function in $\log$ form is:

$$
\begin{aligned}
& \text { In } Y=\beta_{\circ}+\beta_{1} \ln X_{1}+\beta_{2} \ln X_{2}+\beta_{3} \ln X_{3}+\beta_{4} \ln X_{4} \\
& \quad+\beta_{5} \ln X_{5} \ldots \ldots \ldots \beta_{n} \ln X_{n}
\end{aligned}
$$

The output of rice was converted to value terms in the regression analysis which is represented in the following equation as:

$$
\begin{gathered}
\text { In }(G R)=\beta_{\circ}+\beta_{1} \ln (\text { Seed cost })+\beta_{2} \ln (\text { Bullock } \\
\text { labour cost })+\beta_{3} \ln (F Y M \text { cost })+\beta_{4} \text { ln } \\
(\text { Fertilizer cost })+\beta_{5} \ln (\text { Human labour cost })
\end{gathered}
$$

Where, GR is the gross return obtained from rice cultivation calculated by multiplying the rice output by the price of the output, Seed cost is the value of seed used per hectare in rupee terms, bullock cost is the value of bullock labours used in rupee terms, FYM cost is the value of farm yard manures used in rupee terms, fertilizer cost is the value of fertilizer used per hectare in rupee terms and Labour cost is the wage of human labour used in rupee terms. The coefficients $\beta_{i}(i=1,2,3,4,5)$ are the elasticities of the respective variables with respect to the gross return obtained from rice production, with the assumption that $\beta_{\mathrm{i}}>0$.

\section{Ranking of constraints in rice production at farm level}

Constraints in terms of difficulties faced by the respondents were explored by a simple ranking technique employed to identify and rank the difficulties faced by the respondents in adoption of flood tolerant rice variety in order of degree of difficulty and assigned ranks viz., I, II, III. 


\section{RESULTS AND DISCUSSION}

The socio-economic details of the selected respondents revealed that $23.42 \%$ were educated up to the primary level, $57.14 \%$ were educated up to Class higher school level, and $13.11 \%$ were undergraduates and $6.325 \%$ were graduate and better educated. The operational landholding size was found to be 0.60 ha in the marginal category, 1.28 ha in the small category, and 2.33 ha in the medium category. The cropping intensity was recorded to be $121.68 \%$ for marginal farmers, $131.80 \%$ for small farmers, and $134.88 \%$ for medium farmers. The summary of statistics for variables gathered from the survey are shown in Table 2.

Table 1: Distribution of sample farms according to size class

\begin{tabular}{lll}
\hline Farm size & $\begin{array}{l}\text { Number of } \\
\text { respondents }\end{array}$ & $\begin{array}{l}\text { Percentage of total } \\
\mathbf{( \% )}\end{array}$ \\
\hline Marginal & 28 & 35.00 \\
Small & 22 & 27.50 \\
Medium & 30 & 37.50 \\
\hline Total & $\mathbf{8 0}$ & $\mathbf{1 0 0 . 0 0}$ \\
\hline
\end{tabular}

Table 2: Regression estimates of factors affecting rice production at farm level (Adopters and Non Adopters)

\begin{tabular}{lll}
\hline Explanatory variables & Non-Adopter & Adopter \\
\hline Intercept & $8.63(0.489)$ & $6.007^{* * *}(1.905)$ \\
Seed cost $\left(X_{1}\right)$ & $0.007(0.341)$ & $0.515^{* * *}(0.135)$ \\
Bullock cost $\left(X_{2}\right)$ & $0.056(0.039)$ & $0.303^{* *}(0.120)$ \\
FYM cost $\left(X_{3}\right)$ & $0.074^{* *}(0.28)$ & $0.014(0.067)$ \\
Fertilizer cost $\left(X_{4}\right)$ & $0.107^{* * *}(0.013)$ & $0.052(0.042)$ \\
Labour cost $\left(X_{5}\right)$ & $0.016(0.041)$ & $-0.162(0.148)$ \\
\hline Number of observations & $\mathbf{5 0}$ & $\mathbf{3 0}$ \\
\hline $\mathbf{R}^{2}$ & $\mathbf{0 . 6 8}$ & $\mathbf{0 . 6 3}$ \\
\hline
\end{tabular}

Source: Authors' calculations.

Notes: Figures within parentheses indicate standard errors.

*Significant at $10 \%$ probability level; ${ }^{* * S i g n i f i c a n t ~ a t ~} 5 \%$ probability level; **Significant at 1\% probability level.

An attempt was made to find out the effect of the production variable on the rice production for both normal (non adopters) and flood tolerant rice varieties (adopters) in the study area. Rice production was expressed in value terms by multiplying the amount of production by the price and used the gross return as the dependent variable and the independent variable considered were seed cost, bullock labour cost, FYM cost, fertilizer cost and human labour cost. From the Table it was observed that for the non adopters, there was a positive relation of all the factors considered in the model. This positive relation may be inferred that there was scope for increasing the use of these inputs for enhanced rice production. The regression coefficient for seed cost (0.007), bullock cost (0.056), labour cost (0.016) were found to have influenced the gross return positively, though not significantly. FYM cost (0.074) and fertilizer cost (0.107) were found to be positive and significant indicating that with $1 \%$ increase in both the inputs would increase the rice production and thereby increase the gross return by 7.4 and 10.7 per cent, respectively. For the adopters, all the inputs except labour cost $(-0.162)$ were found to have positive influence on rice production. It may be inferred from the negative sign of the labour cost that hired use of human labour was more than the required amount. Seed cost (0.515) and bullock cost (0.303) were found to influence rice production positively and significantly indicating 51.5 and $30.3 \%$ increase in gross return with one $\%$ increase in these two inputs. Farmers were using a good quantity of manure that would help in higher gross returns. Koirala et al. (2014) reported that fuel, fertilizer, land rent, planting season, and land area are the factors that affect both production and technical efficiency of rice production in the Philippines. A positive significant effect of fertilizer and family labour on rice production in Nigeria was reported by Sadiq et al. (2020).

In their study on production efficiency of rice in Nagaland, Longkumer and Giribabu (2019) found that human labour had positive significant impact on rice production. In the study area the adoption of flood tolerant rice varieties were found to be in $41.03 \%$ of the total rice area. The problems were sorted and depicted in the descending order and percentage ranking was given against each problem and the observations are presented in Table 3 and 4. Among adopters, the major problem observed was high seed cost according to $33.33 \%$ of total adopters. Inadequate finance available for cultivation was ranked as second problem with $20.00 \%$. Pests and diseases were also one of the most recurring problems and ranked as III with $16.66 \%$. Untimely supply of seed was another problem 
which sometimes caused seed failure during the sowing time ranked as IV with $13.33 \%$ followed by problems like flood with water hyacinth. Mustapha et al. (2012) found that in his study most important (95.63\%) constraint of the respondents in adopting rice production technologies was unavailability of improved seeds (93.63\%), poor extension services $(47 \%)$

Table 3: Problems faced by farmers adopting flood tolerant rice varieties in the study area $(n=30)$

\begin{tabular}{|c|c|c|c|}
\hline Types of the problem & $\begin{array}{l}\text { Adopters } \\
\text { (No.) }\end{array}$ & Percentage & Rank \\
\hline High cost of seed & 10 & 33.33 & I \\
\hline Inadequate finance & 6 & 20.00 & II \\
\hline Pests and diseases & 5 & 16.66 & III \\
\hline $\begin{array}{l}\text { In adequate supply of } \\
\text { seed }\end{array}$ & 4 & 13.33 & IV \\
\hline Untimely supply of seeds & 3 & 10.00 & $\mathrm{~V}$ \\
\hline $\begin{array}{l}\text { Flood water with water } \\
\text { hyacinth }\end{array}$ & 2 & 6.66 & VI \\
\hline
\end{tabular}

Source: Authors calculation.

Table 4: Problems faced by non-adopter farmers in the study area $(n=80)$

\begin{tabular}{llll}
\hline Types of the problem & \multicolumn{2}{l}{$\begin{array}{l}\text { Non-Adopters Percentage } \\
\text { (No.) }\end{array}$} & Rank \\
\hline $\begin{array}{l}\text { Lack of awareness } \\
\text { about flood tolerant rice } \\
\text { varieties }\end{array}$ & 15 & 30.00 & I \\
$\begin{array}{l}\text { Lack of extension } \\
\text { contacts }\end{array}$ & 13 & 26.00 & II \\
$\begin{array}{l}\text { Inadequate supply of } \\
\text { seeds }\end{array}$ & 7 & 14.00 & III \\
$\begin{array}{l}\text { High cost of seed } \\
\begin{array}{l}\text { In adequate supply of } \\
\text { seed }\end{array}\end{array}$ & 4 & 12.00 & IV \\
$\begin{array}{l}\text { Flood water with water } \\
\text { hyacinth }\end{array}$ & 3 & 8.00 & V \\
\begin{tabular}{l} 
Size of holding \\
\hline
\end{tabular} & 2 & 6.00 & VI \\
\hline
\end{tabular}

Source: Authors calculation.

In case of non-adopters Lack of awareness about flood tolerant rice varieties with $30.00 \%$ was ranked first among all the problems. Lack of extension contacts was a serious problem due to which they were lacking knowledge about flood tolerant rice varieties as reported by $26.00 \%$ of non adopters. Even if they were aware, lack of availability of seeds of flood tolerant rice variety was another problem for them in adopting those varieties. Inadequate supply of seed was a problem which ranked as III as reported by $14.00 \%$ and followed by other problems. Sharma (2015) reported in her study that insufficient extension services along with lack of access to finance were some of the problem in commercialization in Assam.

\section{CONCLUSION}

For the non-adopters, there was a positive relation of all the factors considered in the model. FYM cost (0.074) and fertilizer cost (0.107) were found to be positive and significant indicating that with $1 \%$ increase in both the inputs would increase the rice production and thereby increase the gross return by 7.4 and $10.7 \%$, respectively. For, the adopters all the inputs except labour cost $(-0.162)$ were found to have positive influence on rice production. Seed cost (0.515) and bullock cost (0.303) were found to influence rice production positively and significantly indicating 51.5 and $30.3 \%$ increase in gross return with one per cent increase in these two inputs. The coefficient of multiple determinations (R2) for both adopters and non-adopters were found to be 0.63 and 0.68 indicating that $63 \%$ and $68 \%$ of the variable considered in the model could explain considerable variations in the gross return from the rice production.

In case of adopters the intercept (1.905) had a positive relation with the production of rice. Farmers have the scope for improving rice production by adopting tolerant rice varieties. For increasing the adoption rate of flood tolerant rice varieties, government should provide facilitative environment for the service providers in areas like private extension and agricultural input supplies. Proper utilization of strategic inputs, imparting trainings to the farmers about the benefits of flood tolerant rice varieties would certainly enhance the yield of the flood tolerant rice varieties in the study area and in the state and thereby can help to increase the farmers income. Among adopters, the major problem observed was high seed cost according to $33.33 \%$ of total adopters. Untimely supply of seed also was another problem which creates seed failure during the sowing time ranked as IV with $13.33 \%$. In case of non-adopters lack of awareness about flood tolerant rice varieties with $30.00 \%$ was ranked first among all the problems. Lack of extension contacts was a serious problem due to which they were lagging 
in knowledge about flood tolerant rice varieties as reported by $26.00 \%$ of non-adopters. These results could help governments and agricultural extension contact agents to design effective interventions to increase production so as to increase famers' income and thereby making more pursuit of happiness.

\section{REFERENCES}

Effendy. 2010. Factor efficiency of production and income level of rice fields in Masani village posopesisir subdistrict poso regency. Journal of Agro Land, 17: 233-240.

Hossain, M., Janaiah, A. and Husain, M. 2003a. Hybrid Rice in Bangladesh. Farm Level Performance, Economic and Political Weekly, 38: 25.

Koirala, K.H., Mishra, A.K. and Mohanty, S. 2014. Determinants of Rice Productivity and Technical Efficiency in the Philippines. In: Proceedings of the Annual Meeting for presentation at the Southern Agricultural Economics Association (SAEA), Dallas, TX.
Longkumer, B.I. and Giribabu, M. (2019). Production Efficiency of Wet Rice and Wet Terrace Cultivation in Nagaland: Some Field Based Evidences. Economic Affairs, 64(2): 351-360,

Mustapha, S.B., Undiandeye, U.C., Sanusi, A.M. and Bakari, S. 2012. Analysis of adoption of improved rice technologies in jeer local government area of Borno state, Nigeria. International Journal of Development and Sustainability, 1(3): 1112-1120.

Sadiq, M.S., Singh, I.P. and Ahmad, M.M. 2020. Resource Use Efficiency of Rice Farmers Participating in Value Chain Development Programme (VCDP) in Niger State of Nigeria. Economic Affairs, 65(2): 129-136.

Sharma, S. 2015. Commercialization of small holders farming in Assam. M.Sc. (Agri.) Thesis (Unpublished), Assam Agricultural. University, Jorhat. 
